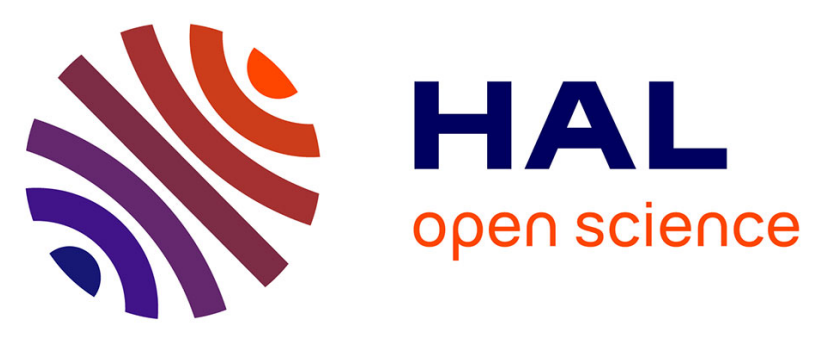

\title{
Measuring the contribution of tumor biobanks to research in oncology: Surrogate indicators and bibliographic output
}

\author{
Véronique Hofman, Marius Ilie, Elodie Long, Kevin Washetine, Christian
} Chabannon, Dominique Figarella-Branger, Bruno Clément, Laurence Mabile, Anne Cambon-Thomsen, Pascal Boucher, et al.

\section{To cite this version:}

Véronique Hofman, Marius Ilie, Elodie Long, Kevin Washetine, Christian Chabannon, et al.. Measuring the contribution of tumor biobanks to research in oncology: Surrogate indicators and bibliographic output. Biopreservation and Biobanking, 2013, 11 (4), pp.235-244. 10.1089/bio.2013.0015 . inserm01978789

\section{HAL Id: inserm-01978789 https://www.hal.inserm.fr/inserm-01978789}

Submitted on 11 Jan 2019

HAL is a multi-disciplinary open access archive for the deposit and dissemination of scientific research documents, whether they are published or not. The documents may come from teaching and research institutions in France or abroad, or from public or private research centers.
L'archive ouverte pluridisciplinaire HAL, est destinée au dépôt et à la diffusion de documents scientifiques de niveau recherche, publiés ou non, émanant des établissements d'enseignement et de recherche français ou étrangers, des laboratoires publics ou privés. 


\title{
Measuring the contribution of tumor biobanks to research in oncology: Surrogate indicators and bibliographic output
}

\author{
Véronique Hofman (1, 2,), Marius Ilie (1, 2), Elodie Long $(1,2)$, \\ Kevin Washetine (1, 2), Christian Chabannon (3), Dominique Figarella-Branger (4), \\ Bruno Clément (5,6), Laurence Mabile \# (7), Anne Cambon-Thomsen \# (7), \\ Pascal Boucher \# (8), Georges Dagher \# (5), Robert Hewitt \# (9), \\ Barbara Parodi \# (10), and Paul Hofman \# $(1,2,5)^{*}$
}

(1) Hospital-Integrated Biobank, Pasteur Hospital, BP 69, 06002 Nice, University of Nice Sophia Antipolis, France (2) Laboratory of Clinical and Experimental Pathology, Pasteur Hospital, Nice, (3) Biobank, Paoli-Calmettes Institute, Marseille, France, (4) Laboratory of Pathology, Timone Hospital, Marseille, France, (5) Inserm National Biobank Infrastructure, Paris, France; (6) Inserm, UMR-991 and Biobank, CHU Pontchaillou, University of Rennes-1, Rennes, France; (7) UMR Inserm 558, University of Paul Sabatier, Faculty of Medecine, Toulouse, France, (8) French National Cancer Institute, Boulogne, France, (9) Biopreservation and Biobanking, Aix-en-Provence, France, (10) Cell Bank, National Cancer Research Institute, Genova, Italy Running title: Performance indicators in biobanking field \# These authors are member of the BRIF group (http://www.gen2phen.org/groups/brif-bio$\underline{\text { resource-impact-factor) }}$

*Correspondance : Paul Hofman, adresse ci-dessus; tel : 04920388 55; fax : 04920387 50; E-mail : hofman.p@chu-nice.fr, 


\section{Summary:}

The number of biobanks, in particular hospital-integrated tumor biobanks (HITB), is increasing all around the world. This is the consequence of an increase in the need for human biological resources for scientific projects and more specifically for translational and clinical research. The robustness and the reproducibility of the results obtained depends greatly on the quality of the biological samples and the associated clinical data. They also depend on the number of patients studied and on the expertise of the biobank that supplied the samples. The quality of a research biobank is undoubtedly reflected in the number and overall quality of the research projects conducted with samples provided by the biobank. Since the quality of a research project can be measured from the impact factor of resulting publications, this also provides some indication of the quality of a research biobank. However, this method of assessment faces a number of major problems: the first is that the delay between the initiation of a research project (including securing access to human resources from a biobank) and its conclusion with one or several publications may take several years; the second is the lack of consensus in the research community of the form of acknowledgement of the biobank's contribution (authorship versus mention in one of the sections of the manuscript), which currently makes automatic bibliographic retrieval unreliable: the third is that high quality samples do not ensure high quality research. Equally, it is conceivable for poor quality samples to be used for research that is published in high impact journals. It is therefore necessary for the biobank community to define additional "surrogate" quality indicators, and establish systems of evaluation, in relation to current and future resource requirements. These indicators will help in the realistic assessment of biobanks by institutions and funding bodies and they will help biobanks to demonstrate their value, raise their quality standards and compete for funding. Given that biobanks are expensive structures to maintain, funding issues are particularly important especially in the current economic context. Use of these indicators may also contribute to the development of a biobank impact factor or "bioresource research impact factor" (BRIF). Herein we review four major categories of indicators (describing the quality, the activity, the scientific productivity, and the "visibility" of the biobank) that seem to us to be useful for the evaluation of a HITB. In addition, we propose a scoring system to measure the different items discussed.

Key Words: Biobank, hospital-integrated tumor biobank, indicators, BRIF, translational research 
Introduction: New challenges in biobanking and consequences for the hospital-integrated biobanks

When considering the high number of biobanks in Europe and other parts of the world and the increase in competition between these research infrastructures, it is important to define performance indicators in order to evaluate to what extent they meet the needs of different private and public partners [Cambon-Thomsen, 2003; Hewitt and Hainaut, 2011; Womack and Gray, 2009]. Hospital-integrated tumor biobank (HITB) deliver samples or series of samples for the purpose of better understanding the physiopathology of diseases and/or better defining and validating new diagnostic, pronostic and/or theranostic biomarkers [Hewitt, 2011]. In this regard, the growing number of requests for high quality biological resources, in association with clinical data, requires that HITBs have an efficient turn around time between sample request and sample delivery.

The creation and follow-up of biobank indicators should aim to optimize HITB operations and ensure their sustainability. Potential criteria for biobank evaluation are numerous. Their category and priority need to be defined to guide their introduction into routine practice so that they can be used by the different stakeholders as well as funding agencies.

\section{Proposal of four large categories of indicators for a hospital-integrated tumor biobank}

The purpose of the article is to review several potentially useful types of indicators, and to assess their advantages and caveats as tools for HITB evaluation. These indicators have been classified into four broad categories which describe and cover various aspects of HITB 
operations: 1) indicators related to quality; 2) indicators related to activity; 3) indicators related to scientific productivity and, 4) indicators related to external dissemination and communication.

For items within each of these four categories we have assigned arbitrary scoring coefficients. The list of these items is not exhaustive and many other criteria may be integrated in the future, depending on the strategic orientation of the HITB.

Scoring systems will need to be adjusted to provide comparable assessments of biobanks with different missions and strategic orientations. At one extreme there are biobanks that act purely as service providers for private or public partners. At the other extreme there are biobanks that play an active role in scientific projects and develop their own research. Depending on its internal organization, its motivation and also on its business plan, an HITB may function using one or a combination of these two "patterns". It is important to measure to what extent, and for which proportion of the research projects, the HITB contributes to the research. This can include performing some of the analytical assays and experiments, the collection and update of clinical data, and the final interpretation of the experimental data, beyond the "simple" delivery of biological resource; in other words, it is important to evaluate the extent and quality of the connections and collaborations established between the HITB and other hospital-based resources and infrastructures (such as the pathology department, the molecular diagnostic department or other) and resources and infrastructures purely dedicated to research activities.

\section{Indicators relating to quality}

The different indicators of the quality of an HITB and the corresponding item coefficients are listed in table 1. 


\section{The quality of biological resources}

- The quality control of the morphology of frozen tissue samples is an essential parameter. This point highlights the obvious necessity to set up a tight collaboration between the pathologists and the biobankers [Bevilacqua et al]. The morphological controls performed must be representative of the frozen sample. This is a critical point since the different analyses performed with frozen tissue (using biochemical and molecular biology technical approaches) have to be done from representative samples of the lesions of interest. This step is particularly important when omic project are developed further, since results can vary considerably depending on the relative proportion of tumor cells, stromal cells and infiltrating inflammatory cells as well as the presence of necrosis. The morphological assessment of tissue samples can be done in various ways depending on the laboratory practice, and each method has advantages and disadvantages. One method is to obtain a formaldehyde fixed paraffin embedded (FFPE) tissue sample to mirror the sample dedicated to the freezing procedure, and to stain sections for assessment and archiving by the biobank. The disadvantage of this approach is that the FFPE tissue sample may not accurately represent the whole frozen tissue sample. However, this method allows in parallel performance of immunohistochemical studies on whole sections and secondary tissue microarrays. It is probably good practice to keep these FFPE tissue blocks at $4^{\circ} \mathrm{C}$ for collection of high quality and well preserved FFPE tissue blocks (in particular to plan in the long-term molecular biology analyses from these fixed tissues). Another method is to perform imprint cytology of the tissue sample before freezing. This method is rapid and allows one to check whether the tumor lesion is really present and whether there is a sufficient number of tumor cells before freezing. However, quality control of the morphology is only partially reliable since the architecture is not available on these imprints. 
Moreover, a potential risk of external contamination exists for tissue specimens when using this procedure. Finally, another method is to cut a frozen section of the selected tissue immediately before nucleic acid and/or protein extraction. This approach is also called the «sandwich technique », since tissue sections for morphological analysis have to be cut on either side of the section cut for nucleic acid and/or protein extraction. This method allows for excellent quality control of the frozen lesion morphology (percentage of tumor cells, area of necrosis, stroma component). However, the disadvantage of this method is that it raises the temperature of the whole frozen tissue sample from $-80^{\circ} \mathrm{C}$ or below up to at least $-20^{\circ} \mathrm{C}$ (the temperature of the cryostat). This can be a disadvantage if the remainder of the tissue sample needs to be returned to a lower temperature for future projects. Moreover, external contamination can occur using this procedure. Whatever the laboratory choice for control of morphology, it is critical to archive the corresponding images using software that allows comparison of histology with the biochemical and/or the molecular data, obtained from the corresponding frozen specimen.

- It is important to assess the quality of the nucleic acids obtained by extraction of the frozen sample). DNA is more «resistant » than the RNA and proteins to the time of warm and cold ischemia, and also to formalin fixation [Ma et al, 2012]. In this regard, it is important to note that even if the pre-analytical time is not optimal, certain DNA samples may be used successfully to detect for genomic alterations in tumor samples. Conversely, other research projects, in particular those using RNA, need to be done from high quality frozen samples and the RNA quality must then be controlled on a bioanalyser. It is widely claimed that samples must have an RNA Integrating Number (RIN) above 7 for most transcriptomic projects. However, this assumption needs to be questioned because some tumor pathologies are often associated with necrotic areas or 
with a large number of hypoxic cells and so a cut-off RIN value of 7 may be inappropriate for some human tissue samples. An elevated RIN (above 7) is indicative of good quality control for cell culture, but an elevated RIN does not reflect the reality of most of the tumor's "quality status" even before surgical resection. In this regard, a large number of tumors (for example some lung, pancreatic and central nervous system tumors) will have an exceptionally lowered RIN even in association with a short time of warm and cold ischemia before freezing [Ma et al, 2012]. Whatever, the requirements and the needs of a research project, it is critical for a HITB to demonstrate the efficacy and the management of the different pre-analytical steps and parameters (recording of the time of cold ischemia, and if possible of the time of warm ischemia, length of freezing or duration of the formalin fixation before paraffin embedding, archive period).

- The the number of specimens and quantity of tissue available is an indicator and the gross weight of the frozen tissue samples in the cryotubes should be evaluated before providing samples for a research project. All cryotubes containing a tissue sample should be weighed with a precision balance before freezing. In this regard, a number of HITBs only provide extracted nucleic acids and/or proteins to their partners in order to better control the quantity of sample dispensed.

- For the same cohort of patients, the availability of samples of different origins such as tissues (frozen and/or FFPE tissues), nucleic acids (somatic and germinal DNA, RNA, microRNA) and proteins, biological fluids (whole blood, plasma/sera, pleural liquid, urine, salivary fluid, etc.), and/or primary cell cultures, can provide added value for research projects. For example, projects targeting the discovery and/or validation of biomarkers can use data obtained from both tissues and biological fluids. Moreover, the possibility of obtaining frozen and fixed tissues (and potentially tissue microarrays) 
from the same population of patients can be useful to validate protein expression. Finally, the possibility of developing primary cell cultures in the HITB would be useful for pre-clinical research projects using mouse xenograft models or for in vitro cellular drug toxicity tests. However, it is critical for all collections to obtain optimal sample quality control tools [Betsou et al, 2013].

- Frozen matched « healthy » tissue (or at least matched non tumor tissue) together with a tumor tissue sample is often used in transcriptomic projects. The availability of such control tissue is another quality indicator for HITBs.

\section{Quality of clinical data associated with bioresources}

- Apart from calibration and metrology projects developed for biological test evaluation or validation, all translational and clinical research projects require clinical, pathological and/or biological data associated with the bioresources. For tumor tissue samples, pathological data may relate to the gross morphology and the histological results (in particular the pTNM staging determined according to the updated WHO classification). For histological data, the minimum data set should include the type of the tumor (according to the latest international classification of tumors), and the codification (Cim-10 and CIMO codification). A "transcodification" table must be made available and used by the biobank software according to the codification system, which can be employed at the national level. The percentage of tumor cells and the percentage of necrotic areas should be registered.

- For some projects, the status of genomic alterations (mutations, translocations, etc.) associated with the tumors should be registered and made available.

- The minimum clinical data set linked to the bioresources must include basic demographic information (age, sex, place of birth) and some supplementary clinical 
data that add value to the collection and to the pathology. For instance this additional data could include the place of birth of the parents of the patient or the ethnicity (according to the laws of the country), some clinical data more specific of a pathology (for example work exposure or tobacco status for lung cancer patients), the follow-up of patients (specific disease survival, overall survival, progression free survival) and the different treatments received.

- The centralization of all the available information for each patient through a secure and searchable database (including a security access code and a secure server environment) will contribute to the optimal efficacy of a HITB.

- Setting up a quality management system, in particular for the follow-up of the clinicobiological data (by creating a dynamic system for data recording) is critical for the sustainability of updating data. Moreover, software for biostatistical analysis must be integrated into this management system.

\section{Ethics}

- Patient informed consent must be obtained before using a human bioresource for a research project. This is mandatory in most but not in all countries [Riegman et al]. However, this requirement has been discussed only recently in certain countries (such as in France) and unfortunately is not required in all countries. Moreover, the laws in this field are changing rapidly, and for example in France it has been mandatory since 2004 to give detailed information to the patient before taking samples for research. Moreover, a patient can refuse that his/her biological resources be used for research. In this regard, the demonstration that formal procedures have been set up to systematically obtain informed consent before collecting patient samples for research is a strong indicator of good practice. 
- The success rate of the consent procedure is an important indicator. The strategy set out to obtain the informed consent has also to be evaluated.

- Collection and storage of the signed consent in a secure place has to be formalized: hard copies signed at least twice must be stored in separate locations and/or scanned and registered in a secure hospital database. This patient informed consent must be checked before using samples for a research project.

- The formulation of terms used on the informed consent sheet must be appropriate. The hospital's ethics committee must check the form. The use of broad consent for several research projects is possible, even though this eventuality is controversial in certain countries [Hanson et al, 2006; Hofmann et al, 2009; Steinsbekk et al, 2013].

- Anonymized personal data: The HITB must demonstrate its ability to protect the personal data of the patients and to show that the biological and clinical data shared with partners does not reveal a patient's identity [Malin et al, 2011].

\section{Miscellaneous parameters related to quality criteria}

- The risk status of patients for human immunodeficiency virus, hepatitis B and hepatitis $\mathrm{C}$ infection is a frequent request when establishing a contract, in particular with industrial partners. However, viral serological testing is not mandatory for all hospitalized patients and can lead to a supplementary cost to some research projects.

- The existence of back-up collections at different locations may also be used as an indicator. These may be fully or partially comprehensive and are particularly important for collections of rare tumours. If backup collections are held by a different HITB, this second HITB needs to show the same level of certification or accreditation as the first. For example these HITB need to be certified according to the NF S96-900 in France. 
- The efficacy in locating samples and the associated data in the database, and thus a good turn around time between the request and delivery of samples needs to be evaluated.

\section{Coefficients}

The coefficients assigned to each main item described above in table 1 have been given arbitrarily. We would argue that the criteria corresponding to the «informed consent » should have at least the same coefficient as those concerning the « intrinsic quality » of the samples.

\section{Indicators related to activity}

The different indicators related to the activity of an HITB and the proposed coefficients for the items are listed in table 2 . The term "activity" does not concern an analytical count only, but includes other miscellaneous criteria.

\section{Storage and supply activity}

- This item corresponds to analytical count criteria taking into account the number of samples collected per year (tissues, biological fluids, etc.) and the number of samples supplied per year for use in research projects. As an example, at a national level, this item is a strong parameter, which is taken into account in the HITB evaluation process by the French National Cancer Institute (INCa) in France [http://www.ecancer.fr/recherche].

- The criteria used to measure the ratios between the storage and supply are dependent on a number of issues: 1) the type of collection being considered (organ, pathology) 2) the type of samples (tissue, nucleic acids, biological fluids, etc.), or, 3) the global activity of 
the HITB. The stored data needs to include the number of collected samples for each patient. In France, it is possible to use the budgetary nomenclature set up in Montpellier to evaluate this activity [htpp://www.chu-montpellier.fr/publications/rubrique.jsp]]. Different activities can thus be evaluated, such as the number of tissue samples, of aliquots of plasma/sera, of paraffin sections, of patient tissue specimens included in tissue microarrays, etc. This meticulous work is in fact useful to obtain an objective evaluation of the global activity performed in a HITB.

- Strategic planning taking into account the different results has to be set out at least annually to reduce or to increase the number of samples for storage in the HITB. This strategic approach has to be linked to the number of projects developed each year using the same collection and also to the available annual HITB budget.

- In the extreme situation, it may be decided to destroy certain stored collections if there has been no sample transfer for a long period time.

\section{Management of HITB team workers}

- The required number and type of HITB team workers can be directly determined from previously defined criteria for evaluation of activity. The sample turnover (which is objective proof that samples stored in the HITB are used in research projects), is useful for anticipation of workload and planning purposes. The absence of specific expertise in management of the staff (pathologist, biologist, technician, data manager, secretary) can lead to a slowdown in the HITB activity despite growing demands for samples.

\section{Biological resource pricing and setting up a business plan model}

- The pricing of human samples is difficult to evaluate and depends on the organization of the HITB. However, setting up a pricing policy for a HITB is a key factor in 
determining where and how investments will be made. This point is critical in optimizing the running of the HITB and also in maintaining the infrastructure of the HITB [htpp://www.e-cancer.fr/recherche/les-ressources-biologiques].

- The pricing policies developed by the HITB have to be approved by the hospital management. This pricing must be clearly stated in the contract before the formal request of samples and before setting up a research project.

- A clear business model is necessary to anticipate the sustainability of the expenses for manpower (can be maintained, reduced or increased), for the maintenance of the equipment of the HITB and for purchase of consumables.

\section{Turn around time for transferring biological resources}

- The turn around time (TAT) between the request for samples and their transfer to the researcher/partner is an indicator of the efficiency of the whole HITB system, including not only the HITB's team (general manager, data manager, pathologist, biologist, technician, secretary), but also the scientific committee and the hospital administration (for contract validation and signature of the material transfer agreement).

- The TAT efficiency is evaluated according to the nature of the inquiry: number and type of samples, the different origin of the biological resources (tissue plus plasma plus RNA for the same patients for example), the number and type of clinical data associated with samples.

- In this regard, it is certainly advisable to give the different TAT which depend on the request and thus to provide the necessary information concerning these TAT in the contract. 


\section{Dynamic monitoring indicators}

- Selected and miscellaneous indicators can be included here, such as the number of contracts signed per year (number of contracts with private and/or public partners). The level of collaboration with local, regional, national and/or international academic and/or industrial partners should also be monitored.

- Material transfer agreements and contracts made with foreign countries require particular attention to ensure enforcement of the laws for sample transfer. Demonstrating the sustainability of the quality of the management of the HITB is thus an important guarantee for the different partners [Kiehntopf et al, 2011].

- The management of the nonconformities that occur in the HITB: The kind of preventive and corrective measures made and their effectiveness should be recorded..

- Regular statistical tests to check the consistency of data on the central HITB database must be done to assess the number of mismatches.

\section{Coefficients}

Sample transfer, the establishment of pricing for samples and good management of dynamic indicators are major items of this category.

\section{Indicators related to scientific productivity}

The indicators related to scientific productivity are listed in table 3 . It is critical that public hospital biobanks take into account these indicators. The integration of these indicators depends on the goals of the specific biobank. If the main role of a given biobank is to transfer human biological resources of high quality to academic and/or private partners and in exchange to obtain funding, then scientific productivity is not a relevant or critical indicator. Conversely, 
scientific productivity is very important in the evaluation of academic biobanks. In this case, the scientific productivity can also include the team's expertise in research and development. Development of translational research activities within the biobank gives added value to the structure and motivates the HITB team by giving better external visibility. For example, the system called SIGAPS (a software system documenting the scientific publications according to different criteria) has been set up in France in order to assess the hospital departments (which can include the HITB). According to the number of attributed points, more or less funding can be allocated to the different teams. The different items related to scientific productivity are detailed below.

\section{Scientific publications}

- This item must be well defined since it is quite often difficult to know the precise contribution of the HITB to a publication. Moreover, the use and final outcome of biological resources after transfer from the HITB to scientist can be difficult to follow by biobankers. The contribution of the HITB can take different forms. Biobankers can be listed as co-authors of the publication. In this case it will be of interest to check whether the biobanker is the principal investigator in the research work or if he/she is an associated contributor of the publication. The biobank member should then be listed in association with the name of the biobank.

- The contribution of the biobanker (s) listed as an author (s) of a publication has to be clearly indicated (as required currently by some scientific journals at the end of the publication) and in general this work should not be limited to transferring samples.

- A biobank member (manager, pathologist, biologist, technician, etc.) can be cited in the "Acknowledgments" section of the publication and the HITB partnership should appear in this section. The HITB itself can also be cited in this section. 
- The HITB must be listed in the "Materials and methods" section of the publication, if the samples provided were used to obtain results for the publication.

- The BRIF working group is currently developing a framework for: i/ creating a tool for calculating research impact of bioresources based on a metric (algorithm) and a unique digital resource identifier, ii/ assessing requirements for citation/acknowledgement of bioresources in order to trace their use in research [Cambon-Thomsen et al, 2011]. Each collection of a biobank would be assigned a digital object identifier (DOI). Thus for each submitted publication (in which the work or part of the scientific work used biological resources), this DOI would be systematically referred to when submitting a manuscript for review.

\section{Impact factor}

- The quality and the value of the scientific work is mostly linked to the current «scientific world system » and to the reputation of the journal in which this work is published. Each journal has an impact factor, which is higher in the more prestigious scientific journals. Although other criteria can exist (such as the citation index of the publication), the impact factor of the journal is the indicator the most frequently used by the different evaluators of the members, teams, and larger structures (departments, hospitals, universities). A cumulative value of impact factors per year can then be calculated in different ways (according to the presence or not of a biobanker in the list of the authors, according to the position among the authors of a biobanker member, etc.). For each collection this impact factor may also be calculated in a similar way. The same approach could be used to indicate the quality and the richness of a specific collection stored in a HITB and this could be used to justify strategies aimed at 
increasing the number of stored samples corresponding to a specific pathology or organ.

\section{Patents, scientific communications at meetings and reports}

- It is necessary to distinguish between the patents obtained subsequent to research performed in the HITB (such as an innovative test for sample quality evaluation) and patents obtained by research teams using samples transferred from the HITB.

- Books and chapters of books in the field of biobanking and popular science publications can be listed.

- Participation in scientific committees organizing conferences on biobanking themes, and invitations to give lectures at conferences are indicators of scientific activity.

- Oral presentations and posters at meetings (at the national or international level) can be taken into consideration (provided the author (s) is (are) members (s) of the HITB and/or the HITB is listed in the abstract).

\section{Grants}

- Success in obtaining research grants is an important indicator for a HITB. National and international grants must then be recognized [Wescott et al, 2012]. Further distinction should be made between grants obtained by the HITB itself or by team researchers associated with the HITB (and using samples transferred from the HITB)

\section{Coefficients}

The coefficients could be attributed to the cumulated impact factor per year and to the grants obtained. 


\section{Indicators of HITB reputation}

This group of indicators is listed in table 4. It contains heterogeneous items aimed at ensuring the visibility of the HITB at the local, regional, national and international level. As the number of HITB all around the world is increasing, creating a competitive environment, visibility is an essential part of a HITB's work.

\section{Certification, accreditation and different labels}

- The certification of a HITB is mostly related to the use of biological resources for research projects (not for immediate health care of patients). A biobank can be certified according to different types of certification such as the ISO 9001 certification. The certification according to the norm S96-900 is specific to biobank certification in France. This latter norm includes a management quality system, as well as some other specific business requirements in the biobanking field. This norm could be upgraded in the future to become an ISO norm.

- A couple of accreditations, such as the ISO17025 accreditation norm, can be used by the HITB to establish transfer of calibrated products of excellent quality. In addition, certain accreditations are more appropriate for medical biology laboratories, such as the ISO 15189 accreditation, which can be attributed to a HITB if samples are dedicated to diagnostics, prognostics and/or theranostics of the hospitalized patients. 
- Other labels for HITB can exist, such as, the "IBISA" label in France. The latter label certifies that the biobanks have a working technological platform and develops innovative projects using biological samples (for example the improvement of nucleic acid extraction, etc.)

\section{National and international networking}

- The participation of the HITB in national and international networks demonstrates recognition and involvement of the HITB members in the biobanking field [Hewitt and Hainaut, 2011]. A large number of HITB networks exist all around the world. In France different thematic networks have been set up for different biological samples and concern liver or lung cancers, lymphomas and sarcomas or mesotheliomas [htpp://www.e-cancer.fr/recherche].

- Networks of HITB working on the same pathology in association with research projects can be set up. Through these networks, an optimal number of samples of rare pathologies can be obtained for a specific research project [Lochmulle and Schneiderat, 2010].

\section{Membership to biobanking scientific societies and international biobanking groups}

- As an example, in France the INCa has set up a group of experts working at the national level to promote good practice for the use of biological samples. This group regularly provides detailed guidance in different areas of biobanking such as pricing and cost recovery evaluation. This guidance is transmitted to the HITB managers as well as to the hospital authorities.

- Different international organizations in the biobanking world have been set up in recent years, such as the Biobanking and Biomolecular Resource Research Infrastructure 
(BBMRI), the International Society for Biological and Environmental Repositories (ISBER) and the European, Middle East and Africa Society for Biopreservation and Biobanking (ESBB). Through the organization of symposia and meetings, or through the diffusion of guidelines, these different organizations share procedures and ideas to improve the activities of the HITB [Kiehntopf and Krawczak, 2011; Yuille M et al, 2008]. Belonging to one or more of these societies allows managers and staff to stay in touch with the latest developments in the field.

\section{Educational programs and dissemination of the information}

The development of HITBs and the specificities of the work involved has let to the development of a new job description. It is obvious that the management of a HITB has to be done by a "biobanker" who has gained the knowledge and technical skills necessary to succeed in this specific job [Morente et al, 2008]. However, people working in HITBs have a number of different professional backgrounds (pathologist, biologist, technician, data manager, scientist, quality controller, statistician, etc.) and each actor brings a specific contribution. HITB managers and staff benefit from a comprehensive understanding HITB work including quality control procedures, data management, setting up of contracts and material transfer agreements, business plan development, etc. For this reason, it is critical to be able to offer to HITB managers and staff with opportunities for continuing professional training

- The professional training can be done at different levels: 1) in the HITB through the organization of different internal meetings, 2) in the faculties (faculty of medicine or faculty of sciences) through different diplomas such as the master's degree) and 3) in the hospitals in different departments. In this regard, the creation of a Master's degree dedicated to biobank management has been set up in France [http://www.estbb]. 
HITB training course attendance and diplomas provide evidence of the competence of HITB personnel. It is important to take into account any complimentary competence of the HITB members.

\section{Integrated technical platforms}

A number of different technical platforms can be developed in a HITB, including: 1) a platform for nucleic acids extraction and quality control (spectrophotometer, bioanalyser), 2) a biopathology platform (paraffin embedded tissues, tissue micro arrays, immunohistochemistry, in situ hybridization), 3) a molecular biology platform (DNA cycler, sequencing), 4) a transcriptomic platform (scanner for different chips, bioinformatic expertise), and/or 5) other more specialized platforms including laser capture microdissection, primary cell cultures, and proteomic analysis. These different platforms can be integrated and located in the HITB or can be associated with the HITB through different contracts or partnerships. This item does not concern HITBs that only work as secure storage areas for biological samples and do not participate in translational and clinical research projects.

\section{Marketing activity}

Increasing the visibility of the biobank to the community can be done through different forms of marketing. Indeed, having a website, a HITB brochure, and organizing meetings or publishing articles for the general public about the activity of the HITB can all be part of the marketing activity.

\section{Patient involvement}


Active participation of patients and patient representatives in some HITB committees should to be considered.

\section{Partnerships with Industry}

This is most certainly one of the current most important indicators attesting to the attractiveness of the HITB in showing its capability to rapidly provide high quality samples. This indicator also provides evidence of the sustainability and capacity to obtain private funding. Partnerships with industry can be set up through scientific collaboration (patents, communications, publications) or through contracts for sample transfer, but without any scientific collaboration.

\section{Coefficients}

The aim of HITB certification is to obtain a high coefficient. Certification is the guarantee of a highly organised collection and the supply of biological samples of high quality. The HITB's involvement in international networks and scientific collaborations with industrial partners should also obtain high coefficients.

\section{Toward a new system of appraisal of performance of HITB using the coefficients assigned to each category?}

Ratings systems for evaluation are never perfect and they can sometimes be considered as an arbitrary means of arriving at a conclusion. However, the establishment of different coefficients based on various items classified into large categories, as described above, can give an objective idea of the efficacy of a HITB. The most sensitive point probably lies in determining the value of each coefficient according to the considered item. The coefficients given here are very informative but may be improved in the future. According to the total value obtained in 
each of the four large categories of indicators, 5 different ratings could be proposed; for example for a HITB: A+ or "excellent" (>200), A or "very good (150-200), B or "good" (150200), C or “moderate” (120-150), and D or “weak" (<120) (figure 1).

\section{Conclusion}

The establishment of "monitoring indicators" for HITBs aims to maintain the quality of the different procedures, in particular those set up during the time prior to certification or accreditation. These indicators can participate in achieving durable optimization of the HITB. The indicators detailed above can also evaluate other criteria of the running of the HITB, such as the added value of the infrastructure through scientific publications. The list of items described above is not definitively or rigidly fixed and we hope to be able to add other criteria in the future that could be of potential interest for HITB evaluation. The research activity of a HITB can be evaluated in different ways: Based on assessment of resulting translational and clinical research and also based on additional indicators such as patents, consulting activities and different expertise, organization of national or international symposiums or meetings, etc.

Implementation of the BRIF project [http://www.gen2phen.org/groups/brif-bioresource-impact-factor] has rapidly defined indicators for HITB [http://www.gen; CambonThomsen et al, 2011]. In a complementary manner, transmission of an annual activity report (for example, the requirement set out by the INCa in France in the last two years) is another indicator of HITB activity over time.

HITBs usually have no scientific evaluation by the different institutions (for example, in France the research institutions Inserm or CNRS do not perform any evaluation). So currently, 
there is no rating system leading to a "label of excellence" and thus it is not easy to obtain funding through this kind of notation. One reason for this could be the actual absence of an evaluation grid for HITBs that includes objective criteria. In this regard, establishment of indicators could be of interest to set up this evaluation process. The different attributed coefficients outlined in this review are open to discussion and can be modified in the future, in particular when taking into account the "type" and the aim of the HITB, and the different objectives of the HITB. Indeed, some HITBs may not be involved at all in scientific research projects and may have as their unique goal the collection, storage and transfer of biological samples to public and private partners. In this latter case, the indicators concerning the scientific productivity of the biobank are not applicable.

Rating into categories A+, A, B, C or D may be welcomed by the "field workers", and thus may give a reductionist view of the HITB's activity. Different actors may perceive the rating system in a negative way. However, the multiplicity of HITB all around the world, has increased the overall cost of these infrastructures and the need to ensure the sustainability of the staff working in the HITB. This has brought on an urgent need to evaluate the HITB to at least check their efficacy in delivering samples for translational and clinical research. The consequences of such an evaluation may lead to an improvement in the functioning of these infrastructures in different ways, in particular by the optimization of certain targeted collections. In this regard, some synergistic programs involving different HITBs could be set up to obtain a high number of samples with high quality and thus develop excellent research projects.

Conflict of interest: The authors declare no conflict of interest 
Acknowledgements: The authors wish to thank the BRIF group for helpful discussion during the preparation of the manuscript 


\section{References}

Bevilacqua G, Bosman F, Dassesse T, Höfler H, Janin A, Langer R, et al. The role of the pathologist in tissue banking: European Consensus Expert Group Report. Virchows Arch 2010;456:449-54.

Betsou F, Gunter E, Clements J, Desouza Y, Goddard KA, Guadagni F, Yan W, Skubitz A, Somiari S, Yeadon T, Chuaqui R. Identification of Evidence-Based Biospecimen QualityControl Tools: A Report of the International Society for Biological and Environmental Repositories (ISBER) Biospecimen Science Working Group. J Mol Diagn. 2013 Jan;15(1):316.

Cambon-Thomsen A. Assessing the impact of biobanks. Nat Genet 2003; 34: 25-26.

Cambon-Thomsen A, Thorisson GA, Mabile L, Andrieu S, Bertier G, Boeckhout M, et al. BRIF workshop group. The role of a Bioresource Research Impact Factor as an incentive to share human bioresources. Nat Genet 2011;43:503-4.

Hansson MG, Dillner J, Bartram CR, et al. Should donors be allowed to give broad consent to future biobank research? Lancet Oncol 2006;7:266-9.

Hewitt RE. Biobanking: the foundation of personalized medicine. Curr Opin Oncol 2011 $23: 112-9$ 
Hewitt R, Hainaut P. Biobanking in a fast moving world: an international perspective. $J$ Natl Cancer Inst Monogr; 2011:50-1.

Hofmann B. Broadening consent--and diluting ethics? J Med Ethics 2009; 35:125-9

http://www.chu-montpellier.fr/publications/rubrique.jsp

http://www.e-cancer.fr/recherche/les-ressources-biologiques/la-tumorothèque-virtuellenationale.

http://www.estbb.fr/master-pro

http://www.gen2phen.org/groups/brif-bio-resource-impact-factor

http://www.e-cancer.fr/recherche/les-ressources-biologiques. Etude des coûts de fonctionnement et recommandations pour la mise à disposition des ressources biologiques à des fins de recherche.

Kiehntopf M, Krawczak M. Biobanking and international interoperability: samples. Hum Genet 2011;130:369-76.

Lochmüller H, Schneiderat P. Biobanking in rare disorders. Adv Exp Med Biol 2010;686:10513. 
Ma Y, Dai H, Kong X. Impact of warm ischemia on gene expression analysis in surgically removed biosamples. Anal Biochem. 2012 Apr 15;423(2):229-35.

Malin B, Loukides G, Benitez K, Clayton EW. Identifiability in biobanks: models, measures, and mitigation strategies. Hum Genet. 2011 Sep;130(3):383-92.

Morente MM, Fernández PL, de Alava E. Biobanking: old activity or young discipline? Semin Diagn Pathol 2008;25:317-22.

Riegman PH, van Veen EB. Biobanking residual tissues. Hum Genet 2011;130:357-68.

Steinsbekk KS, Kåre Myskja B, Solberg B. Broad consent versus dynamic consent in biobank research: Is passive participation an ethical problem? Eur J Hum Genet. 2013 Jan 9. doi: 10.1038/ejhg.

Wescott L, Laskofski M. Grant writing tips for translational research. Methods Mol Biol 2012; 823:379-89.

Womack C, Gray NM. Banking human tissue for research: vision to reality. Cell Tissue Bank 2009;10:267-70.

Yuille M, van Ommen GJ, Bréchot C, Cambon-Thomsen A, Dagher G, Landegren U, et al. Biobanking for Europe. Brief Bioinform 2008;9:14-24. 


\section{Legend of tables}

Table 1. Indicators targeting the HITB quality and corresponding coefficients

Table 2. Indicators targeting the HITB activity and corresponding coefficients

Table 3. Indicators targeting the HITB scientific productivity and corresponding coefficients

Table 4. Indicators targeting the evaluation that aims to raise the profile of a HITB and corresponding coefficients 


\section{Legend of figure}

Figure 1. Global proposal for a HITB evaluation according to the coefficient rating of the different class of indicators 


\section{Table 1}

\section{SAMPLE QUALITY (COEFFICIENT: 20)}

DNA quality and control mode

RNA quality and control mode

Sample quantity and/or available nucleic acids (DNA \& RNA)

Control of morphology and principle (cutting the mirror block, imprint cytology, frozen slides)

Availability of biological fluids and tissue (from the same patient)

Parallel collections (primary cell culture, paraffin blocks, TMAs)

Availability of control non tumor tissue and tumor tissue

Epidemiological data (age, sex, place of birth, ...)

Specific data related to pathology

- Pathological data

- Molecular alteration data

QUALITY OF ASSOCIATED DATA (COEFFICIENT: 20)

ETHICS

(COEFFICIENT: 20)

\section{OTHER PARAMETERS IMPACTING} ON THE QUALITY (COEFFICIENT: 5)
- Clinical data

- Codification system

Data on patient follow-up and collection of dynamic annotations

Procedure for collecting informed consent from patients and security means

Ratio of consent/registered files

Serological status (HIV, HBV, HCV)

Computer system and ability to request data based on the issue

Duplication of the collection 


\section{Table 2}

\begin{tabular}{|c|c|}
\hline $\begin{array}{l}\text { STORAGE ACTIVITY } \\
\text { (COEFFICIENT: 10) }\end{array}$ & $\begin{array}{l}\text { For each collection } \\
\text { For each biological product }\end{array}$ \\
\hline $\begin{array}{l}\text { DESTOCKING ACTIVITY } \\
\text { (COEFFICIENT: 15) }\end{array}$ & $\begin{array}{l}\text { For each collection } \\
\text { For each biological product }\end{array}$ \\
\hline $\begin{array}{l}\text { EXISTENCE OF A DYNAMIC } \\
\text { STRATEGY } \\
\text { (COEFFICIENT: } 5 \text { ) }\end{array}$ & $\begin{array}{l}\text { Based on the ratio «storage/destocking» } \\
\text { Based on the submitted projects }\end{array}$ \\
\hline $\begin{array}{l}\text { HUMAN RESOURCES MANAGEMENT } \\
\text { (COEFFICIENT: 5) }\end{array}$ & Adaptation to the work load \\
\hline $\begin{array}{l}\text { TIME RELATED TO THE PROVISION } \\
\text { OF SAMPLES (COEFFICIENT: 5) }\end{array}$ & $\begin{array}{l}\text { Based on the requested sample quantity } \\
\text { Based on the nature of the requested } \\
\text { biological resource }\end{array}$ \\
\hline $\begin{array}{c}\text { SET UP AND APPLICATION OF A } \\
\text { PRICING SYSTEM AND A « BUSINESS } \\
\text { MODEL »(COEFFICIENT: 10) }\end{array}$ & \\
\hline $\begin{array}{l}\text { SET UP OF DYNAMIC INDICATORS } \\
\text { FOR MONITORING (COEFFICIENT: 10) }\end{array}$ & $\begin{array}{l}\text { Monitoring procedures (non-compliances } \\
\text { and effectiveness of the corrective actions) } \\
\text { Material transfer agreement and contracts } \\
\text { Consistency statistical tests in the data base }\end{array}$ \\
\hline
\end{tabular}




\section{Table 3}

\begin{tabular}{|c|c|}
\hline \multirow{4}{*}{$\begin{array}{l}\text { SCIENTIFIC PUBLICATIONS } \\
\text { (COEFFICIENT: 10) }\end{array}$} & Co-authoring of one of the biobank members \\
\hline & $\begin{array}{l}\text { One of the biobank members is quoted in the } \\
\text { "Acknowledgements" }\end{array}$ \\
\hline & $\begin{array}{l}\text { The biobank is quoted in the «Materials and } \\
\text { Methods» section }\end{array}$ \\
\hline & $\begin{array}{l}\text { The biobank is quoted in the } \\
\text { "Acknowledgements" }\end{array}$ \\
\hline \multirow{3}{*}{$\begin{array}{l}\text { IMPACT FACTORS AND SIGAPS } \\
\text { POINTS (COEFFICIENT: 25) }\end{array}$} & $\begin{array}{l}\text { Cumulative impact factors per annum and per } \\
\text { collection }\end{array}$ \\
\hline & $\begin{array}{l}\text { Cumulative impact factors per annum for the } \\
\text { biobank }\end{array}$ \\
\hline & SIGAPS points per annum and per collection \\
\hline \multirow{3}{*}{$\begin{array}{l}\text { FINALISED RESEARCH } \\
\text { (COEFFICIENT: 10) }\end{array}$} & $\begin{array}{l}\text { Patents } \\
\text { - Achieved through collaboration with the } \\
\text { biobank } \\
\text { - Achieved through biobank research work }\end{array}$ \\
\hline & $\begin{array}{l}\text { Organization of national or international } \\
\text { conferences or symposiums }\end{array}$ \\
\hline & $\begin{array}{l}\text { Books and other activities targeting the } \\
\text { biobanks }\end{array}$ \\
\hline $\begin{array}{l}\text { COMMUNICATIONS } \\
\text { (COEFFICIENT: 5) }\end{array}$ & $\begin{array}{l}\text { Targeting the «Biobanking» thematic area } \\
\text { (national or international) } \\
\text { Associating the biobank (national or } \\
\text { international) }\end{array}$ \\
\hline $\begin{array}{c}\text { CALLS } \\
\text { (COEFFICIENT: 10) }\end{array}$ & $\begin{array}{l}\text { Budget obtained by the biobank (direct } \\
\text { financing) } \\
\text { Budget obtained for the biobank (partnership) }\end{array}$ \\
\hline
\end{tabular}




\section{Table 4}

ISO $9001 / 2000$

NF $\$ 96-900$

CERTIFICATION, ACCREDITATION AND LABELS (COEFFICIENT: 20)

ISO 15189

ISO 17025

IBiSA label

National

NETWORK AND COLLABORATING WORK (COEFFICIENT: 10)

International

National

MEMBERSHIP TO «BIOBANKING » SOCIETIES (COEFFICIENT:5)

International

SPECIFIC TEACHING PROGRAM OR PROFESSIONAL EDUCATION (COEFFICIENT:5)

TEAM EXPERTISE (COEFFICIENT:5)

\section{INTEGRATED OR ASSOCIATED TECHNOLOGY}

PLATFORMS (COEFFICIENT:5)

«MARKETING » (WEBSITE; ADVERTISING

BROCHURE; PRESS ARTICLES; PATIENTS

ASSOCIATIONS) (COEFFICIENT:5)

$\begin{array}{ll}\text { PARTNERSHIP WITH INDUSTRY } & \begin{array}{l}\text { In the framework of a } \\ \text { collaborative research } \\ \text { (COEFFICIENT:10) }\end{array} \\ \text { project } \\ \text { In the framework of } \\ \text { supply of services }\end{array}$




\section{Figure 1}

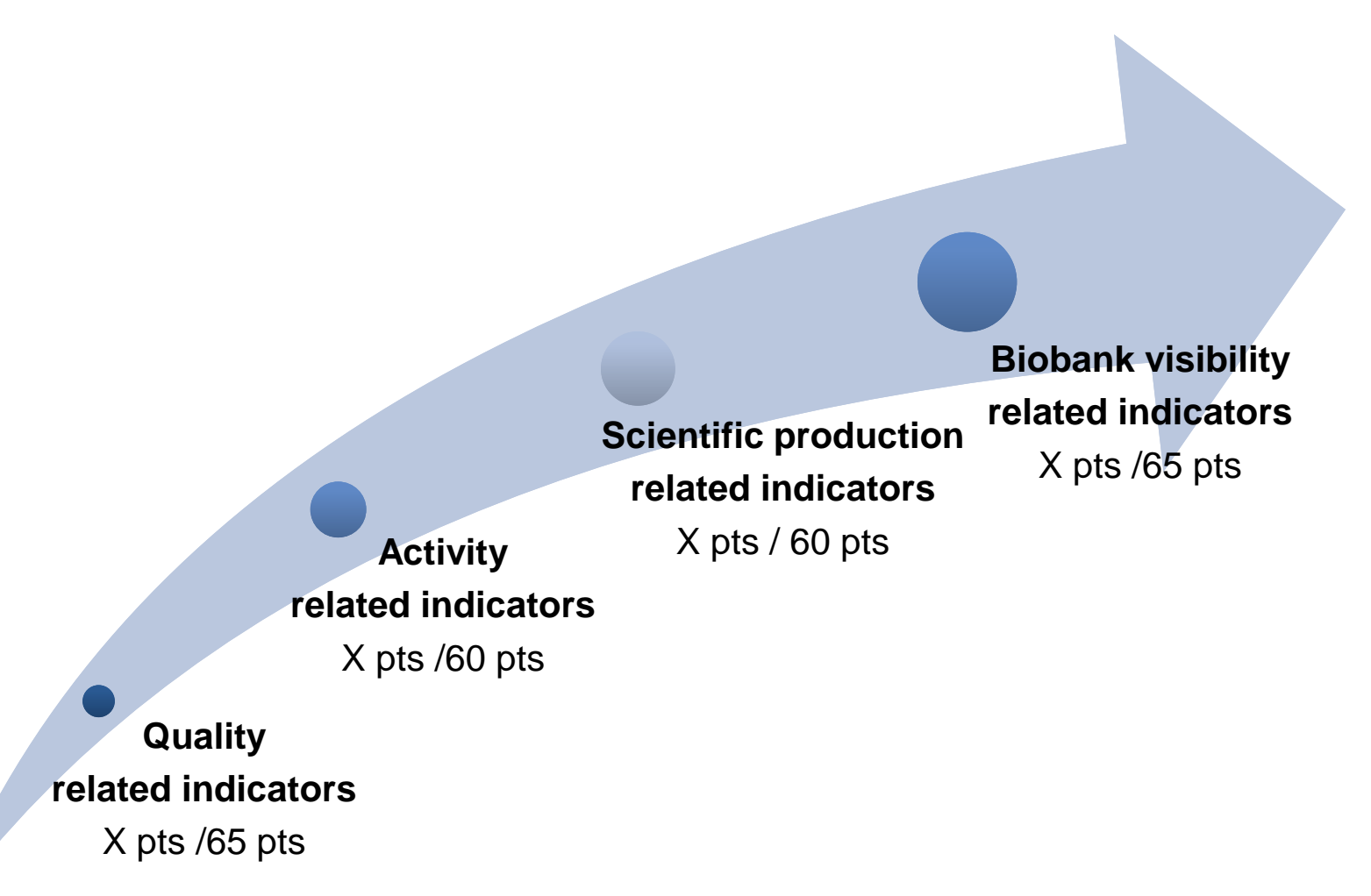

\section{TOTAL: X PTS /250 PTS}

> 200-250: Excellent $(\mathrm{A}+)$

> 150-200: Good $(\mathrm{A})$

$>$ 120-150: Fair (B)

> 100-120: Marginal (C)

$>$ <100: Weak (D) 